\title{
Completion of the Statement of Fitness for Work
}

\author{
Carol Black
}

The Royal College of Physicians was a signatory to the Consensus Statement on Health and Work contained in the Black Review. ${ }^{1}$ This demonstrated a commitment to promoting the link between good work and good health and affirmed that supporting patients to remain in, or return to, work should be part of a healthcare professional's clinical function.

Publication of Completion of the Statement of Fitness for Work: concise guidance in this journal reflects that commitment (pp 63-66). It concerns an aspect of specialist practice that hitherto has not received due attention. Although patients usually look to their general practitioner (GP) to provide a Statement of Fitness for Work, usually known as the 'fit note', the duty does not fall on them alone. A doctor in secondary care might be required to issue a fit note to patients for whom they provide clinical care.

The concise guidance has been prepared by the Department for Work and Pensions (DWP) in association with the Health and Work Development unit at the Royal College of Physicians. It follows DWP guidance which was informed by the review of evidence on the question 'Is work good for your health and wellbeing?' undertaken by Waddell and Burton. ${ }^{2}$ That review provided compelling evidence that for most people of working age the right work is good for their health and wellbeing, and that worklessness is harmful. Further, much sickness absence and inactivity follows common health conditions which, given the right support, are compatible with work - although sometimes it means a different kind of work.

The Waddell review focused on the common health problems that account for most sickness absence from work and longterm incapacity. But the principles of clinical management in relation to function and fitness for work apply to patients with any condition, rare or common. ${ }^{4}$

The fit note serves more than one purpose, but each has a bearing on patient wellbeing.

It offers an opportunity to bring together clinical aspects of illness and the effects on function and the ability to work, and allows doctors to reach a judgement that a patient has some functional limitations but, with appropriate support, could return to the workplace. It is a primary source of shared advice to employee and employer on practical measures that might be taken to enable return.

Employers also use the fit note as evidence of the validity of claims for sick pay, and the state uses it as evidence of eligibility for health-related benefits such as the Employment and Support Allowance. A failure to provide a fit note when it is appropriate

Carol Black, expert adviser on health and work, Department of Health to do so can therefore cause difficulties for patients.

Attention to the fit note as part of a clinical consultation also gives heightened emphasis to the relationship between health and work, with a timely reminder of the importance of work for patient health and wellbeing.

People with long-term sickness absence are at great risk of never working again. For some this is the inescapable consequence of serious illness and disability. For others it might signal a failure to intervene early and effectively when sickness threatens working life.

To inform the advice doctors give, an online resource on health and work has been developed by the Royal College of General Practitioners, the Faculty of Occupational Medicine and the Society of Occupational Medicine. ${ }^{5}$ It contains e-learning designed for doctors in secondary care.

So far the promise of the fit note has been only partly fulfilled. Many people seeking a medical certificate are declared completely unfit. ${ }^{6}$ Such a judgement is wholly warranted when the patient's condition precludes any form of work, either during the time expected for recovery or, in some instances, indefinitely. However, it is acknowledged that judgements about fitness for work are also influenced by psychosocial factors and other complex and subtle factors inherent in the relationship between doctors and their patients, and are not necessarily constrained by the effects of presenting condition alone. ${ }^{4}$ Nonetheless, advice that deters people from returning to work might not, in the longer term, be at all in their best interests.

Naturally doctors see their primary role as the care and treatment of their patients, and restoring function. While sensitive to the costs and burdens of illness and sickness absence that fall on their patients, they are not strongly driven to consider costs to employers and the state. Although cost savings are not seen as a chief purpose of the advice doctors give in the fit note, they might be a beneficial consequence of that advice. ${ }^{6}$

An ideal system would quickly identify people who were unable to work because of sickness or disability, and offer them work-related advice and support. Those with conditions that are compatible with their current work would receive necessary advice and treatment without delay, and be supported and encouraged to return quickly. Individuals for whom a job change was necessary would be helped into new work.

The fit note was conceived to pursue these aims, with a muchneeded emphasis on what, in the face of sickness or disability, a patient could do, rather than what they could not.

Like GPs, few doctors in secondary care settings are trained in detailed functional or disability assessment. That is neither expected nor required. Completing a fit note and advising on fitness for work does not require specialist knowledge of 
workplaces or occupational medicine. But a doctor would be expected to have sufficient understanding of the effects of illness or injury, of treatments in their specialty, and of the likely duration of impaired function, to be able to give clear advice to patient and employer. That advice might include a recommendation for specialised occupational health assessment where, for example:

- the health problem is complex

- the condition is long term

- the treatment is protracted

- there are questions of safety at work

- the working environment itself poses risks to wellbeing.

The recent Review of Sickness Absence ${ }^{6}$ concluded that the fit-note system would be significantly strengthened if doctors were asked to consider an individual's functional capacity to return not only to their own job, but to work more generally. This approach opens ways to return to work that a patient might otherwise not have considered.

A heightened focus on the importance of considering the functional effects of illness and injury, and of finding ways of overcoming them to restore working life, will enrich our clinical practice.

\section{References}

1 Black C. Dame Carol Black's review of the health of Britain's working age population. Working for a healthier tomorrow. London: TSO, 2008

2 Department for Work and Pensions. DWP health and work guidence: statement of fitness for work-med 3. London: DWP, 2010. www.dwp.gov.uk/healthcare-professional/guidance

3 Waddell G, Burton AK. Is work good for your health and well-being? London: TSO, 2006.

4 Coggon D, Palmer KT. Assessing fitness for work and writing a 'fit note'. BMJ 2010;341:1213-7.

5 Healthy Working UK - Learning Resource. www.healthyworkinguk. co.uk. Accessed 9 November 2011.

6 Black C, Frost D. Health at work - an independent review of sickness absence. London: The Stationery Office, 2011.

Address for correspondence: Professor Dame C Black,

Department of Health, Wellington House, 135-155 Waterloo Road, London SE1 8UG.

Email: profblack@btinternet.com

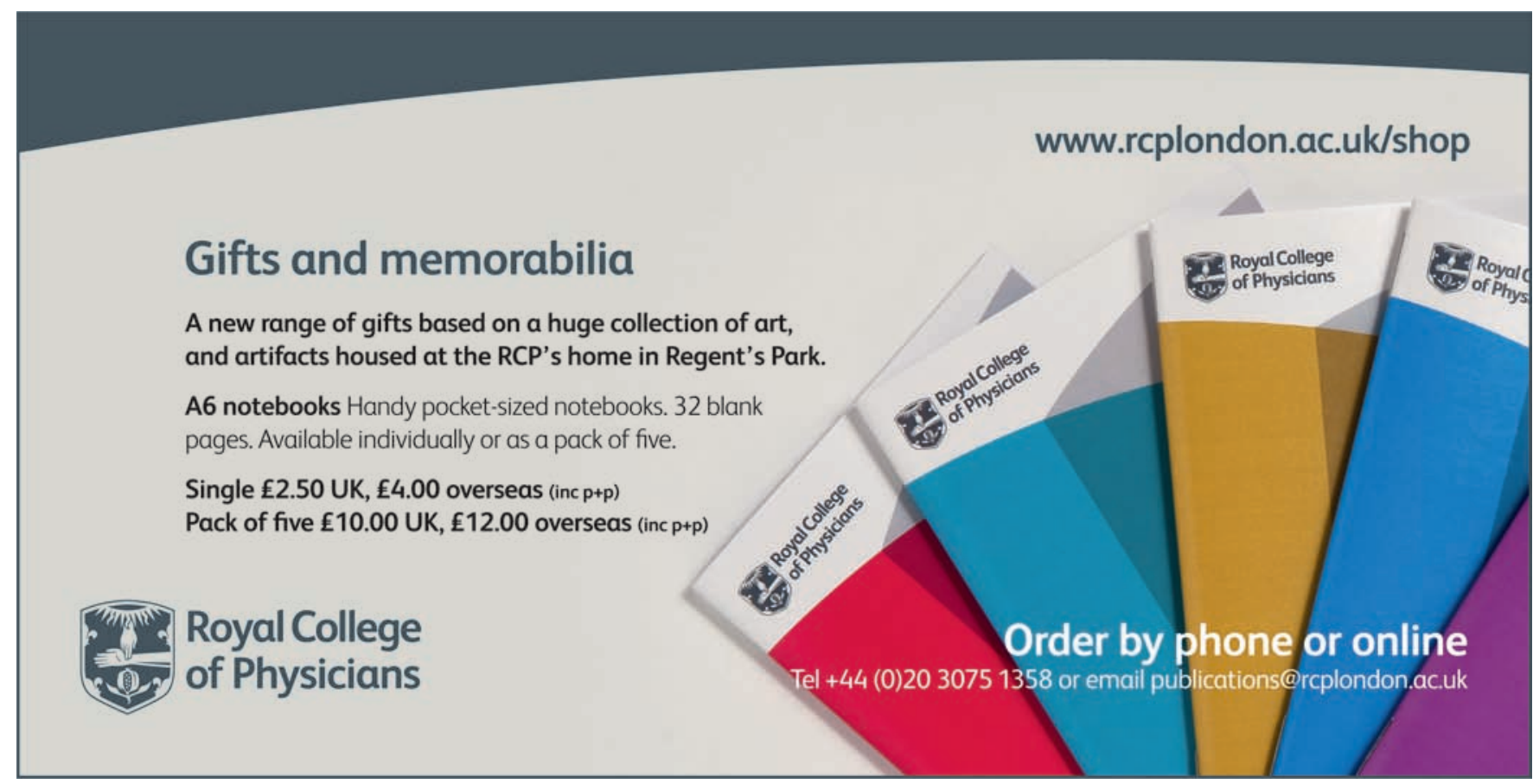

